Western University

Scholarship@Western

Aboriginal Policy Research Consortium International (APRCi)

2010

\title{
HIV testing experiences of Aboriginal youth in Canada: service implications
}

Catherine Worthington

Randy Jackson

Judy Mill

Tracey Prentice

Ted Myers

See next page for additional authors

Follow this and additional works at: https://ir.lib.uwo.ca/aprci

Part of the Health Services Research Commons

Citation of this paper:

Worthington, Catherine; Jackson, Randy; Mill, Judy; Prentice, Tracey; Myers, Ted; and Sommerfeldt, Susan, "HIV testing experiences of Aboriginal youth in Canada: service implications" (2010). Aboriginal Policy Research Consortium International (APRCi). 283.

https://ir.lib.uwo.ca/aprci/283 
Authors

Catherine Worthington, Randy Jackson, Judy Mill, Tracey Prentice, Ted Myers, and Susan Sommerfeldt 
This article was downloaded by: [University of Western Ontario]

On: 30 October 2012, At: 09:26

Publisher: Routledge

Informa Ltd Registered in England and Wales Registered Number: 1072954 Registered office: Mortimer House, 37-41 Mortimer Street, London W1T 3J H, UK

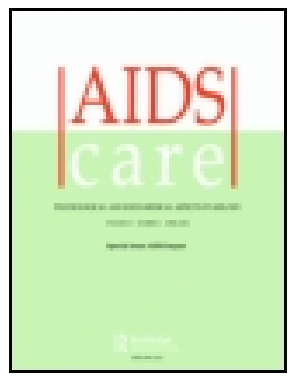

\title{
AIDS Care: Psychological and Socio-medical Aspects of AIDS/HIV
}

Publication details, including instructions for authors and subscription information: http:// www. tandfonline.com/loi/ caic20

\section{HIV testing experiences of Aboriginal youth in Canada: service implications}

\author{
Catherine Worthington ${ }^{a}$, Randy J ackson ${ }^{b c}$, J udy Mill ${ }^{d}$, Tracey Prentice ${ }^{e}$, Ted Myers ${ }^{f} \&$ \\ Susan Sommerfeldt ${ }^{d}$ \\ ${ }^{a}$ Faculty of Social Work, University of Calgary, 2500 University Drive NW, Calgary, AB, T2N \\ 1N4, Canada \\ ${ }^{\mathrm{b}}$ School of Social Work, McMaster University, Hamilton, ON, Canada \\ ${ }^{c}$ Canadian Aboriginal AIDS Network, Vancouver, BC, Canada \\ ${ }^{d}$ Faculty of Nursing, University of Alberta, Edmonton, AB, Canada \\ e Institute of Population Health, University of Ottawa, Ottawa, ON, Canada \\ ${ }^{f}$ HIV Social, Behavioural and Epidemiological Studies Unit, University of Toronto, Toronto, \\ ON, Canada \\ Version of record first published: 15 J ul 2010.
}

To cite this article: Catherine Worthington, Randy J ackson, J udy Mill, Tracey Prentice, Ted Myers \& Susan Sommerfeldt (2010): HIV testing experiences of Aboriginal youth in Canada: service implications, AIDS Care: Psychological and Sociomedical Aspects of AIDS/ HIV, 22:10, 1269-1276

To link to this article: http:// dx. doi.org/ 10.1080/09540121003692201

\section{PLEASE SCROLL DOWN FOR ARTICLE}

Full terms and conditions of use: http://www.tandfonline.com/page/terms-and-conditions

This article may be used for research, teaching, and private study purposes. Any substantial or systematic reproduction, redistribution, reselling, loan, sub-licensing, systematic supply, or distribution in any form to anyone is expressly forbidden.

The publisher does not give any warranty express or implied or make any representation that the contents will be complete or accurate or up to date. The accuracy of any instructions, formulae, and drug doses should be independently verified with primary sources. The publisher shall not be liable for any loss, actions, claims, proceedings, demand, or costs or damages whatsoever or howsoever caused arising directly or indirectly in connection with or arising out of the use of this material. 


\title{
HIV testing experiences of Aboriginal youth in Canada: service implications
}

Catherine Worthington $^{\mathrm{a} *}$, Randy Jackson ${ }^{\mathrm{b}, \mathrm{c}}$, Judy Mill ${ }^{\mathrm{d}}$, Tracey Prentice ${ }^{\mathrm{e}}$, Ted Myers ${ }^{\mathrm{f}}$ and Susan Sommerfeldt ${ }^{\mathrm{d}}$

${ }^{a}$ Faculty of Social Work, University of Calgary, 2500 University Drive NW, Calgary, AB T2N 1N4, Canada; ${ }^{b}$ School of Social Work, McMaster University, Hamilton, ON, Canada; ${ }^{c}$ Canadian Aboriginal AIDS Network, Vancouver, BC, Canada; ${ }^{d}$ Faculty of Nursing, University of Alberta, Edmonton, AB, Canada; ${ }^{e}$ Institute of Population Health, University of Ottawa, Ottawa, ON, Canada, ${ }^{f}$ HIV Social, Behavioural and Epidemiological Studies Unit, University of Toronto, Toronto, ON, Canada

(Received 30 June 2009; final version received 2 February 2010)

\begin{abstract}
The objective of this study was to explore HIV testing experiences and service views of Canadian Aboriginal youth in order to provide information for HIV testing services. An exploratory, mixed-method, community-based research design was used for this study. Findings reported here are from 210 survey participants who had experienced an HIV test. Youth were recruited through 11 Aboriginal organizations across Canada, including AIDS service organizations, health centers, community organizations, and friendship centers. Youth who had tested for HIV ranged in age from 15 to 30 years of age $(20 \%$ were $<20)$, and came from First Nations $(75 \%)$, Métis (14\%), and Inuit (9\%) backgrounds. Participants lived in all provinces and one territory. Over half (62\%) were female. While the majority of survey respondents indicated at their last HIV test they had been treated with care $(80 \%)$, respect $(77 \%)$, or kindness $(76 \%)$, some reported being treated with hostility $(19 \%)$, fear $(12 \%)$, discrimination $(11 \%)$, avoidance $(10 \%)$, or being treated in a bored way $(15 \%)$. When asked about information they had received, $28 \%$ of survey respondents could not remember; $23 \%$ said they were not given any information, and $24 \%$ said their questions were not answered. Emotional reactions to testing ranged from anxiety/apprehension (64\% of survey respondents) to being "calm" (19\%). When asked for suggestions to improve testing services, participants indicated emotional support, compassion, professional yet personable services, and personalized HIV information were important. Study results suggest that to facilitate HIV testing for Aboriginal youth, testing services and counseling must be respectful, compassionate, non-judgmental, and culturally responsive in order to provide emotional support and HIV information that is meaningful and memorable.
\end{abstract}

Keywords: HIV/AIDS; Aboriginal; youth; HIV testing; service satisfaction

\section{Introduction}

Aboriginal peoples (First Nation, Inuit, Métis) comprise only $3.8 \%$ of Canada's total population (Statistics Canada, 2008), but in 2006 accounted for $27 \%$ of new HIV infections in provinces/territories that provide ethnicity data (Public Health Agency of Canada, 2007a). Almost one-third (32.4\%) of the positive HIV test reports from 1998 to 2006 for Aboriginal persons were among those younger than 30 years of age, a rate higher than that of nonAboriginal youth $(21 \%)$ (Public Health Agency of Canada, 2007b). For Aboriginal youth, high rates of teenage pregnancy and sexually transmitted infections (Ontario Federation of Indian Friendship Centres, 2002; Shields et al., 2004), inconsistent condom use (Calzavara et al., 1998), along with feelings of invulnerability and the perception among youth that HIV happens to "other people" in "other communities" (Larkin et al., 2007; Public Health
Agency of Canada, 2007c) contribute to susceptibility to HIV infection. In addition, interactions with HIV prevention services may be influenced by historical inequality and social-structural conditions that promote Aboriginal youths' understandings of HIV as a "death sentence" (Larkin et al., 2007); distinct cultural practices in health care engagement (Smylie et al., 2001); and Aboriginal peoples' distrust of outsiders (Bucharski, Reutter, \& Ogilvie, 2006).

The availability of voluntary, client-initiated testing and counseling is a key component of comprehensive HIV prevention programs (Public Health Agency of Canada, 2006; UNAIDS, 2004). Despite changes to HIV testing guidelines in some jurisdictions that may encourage less test counseling (Branson et al., 2006), HIV test counseling remains central to testing as it provides an opportunity to promote behavior change and potentially control the spread of HIV (Holtgrave \& McGuire, 2007; Norton, Miller, \& Johnson, 1997; Weinhardt, Carey, Johnson, \&

*Corresponding author. Email: cworth@ucalgary.ca 
Bickham, 1999). It also provides an opportunity to link those who test HIV positive to treatment (Hult, Maurer, \& Moskowitz, 2009; Obermeyer \& Osborn, 2007).

From the test provider perspective, best practices in HIV test counseling include ensuring provision of information/education to support HIV risk reduction; individualization of risk assessment and need for psychological support; ensuring test results are given in person; providing HIV information and service referrals; and facilitating partner notification (Myers, Worthington, Haubrich, Ryder, \& Calzavara, 2003). HIV test recipients desire convenient services in a private location where they can receive personalized information and decision-making support about the test in order to obtain appropriate information and allay anxiety and concern over the social consequences and stigma around HIV (Obermeyer \& Osborn, 2007; Worthington \& Myers, 2002, 2003). Although counseling is recommended there is evidence it is not always provided (Monette, Albert, \& Waalen, 2001; Silvestre, Gehl, Encandadela, \& Schelzel, 2000).

The most common reasons youth, including Aboriginal youth, seek an HIV test are because they have been advised by a health care worker; have engaged in a high risk behavior (i.e., injection drug use, unprotected sex); for prenatal screening; or because they are feeling sick (Bucharski et al., 2006; Grant et al., 2006; Mackellar et al., 2006; RotheramBorus, Gillis, Reid, Fernandez, \& Gwadz, 1997; Samet \& Winter, 1997). Very little information is available about youth perceptions on test counseling; however, one study of HIV testing sites in the USA reported that only $28 \%$ of youth said the counselor did a "good" job helping them identify their HIV risk behaviors (Schneir, Belzer, \& Adivi, 1998).

While there is a growing body of work on Aboriginal youth and HIV risk (e.g., Larkin et al., 2007; Marsiglia, Nieri, \& Stiffman, 2006; Mehrabadi et al., 2008), there is little literature that focuses on HIV testing and Aboriginal youth. Given the vulnerability of Aboriginal youth to HIV, the need to develop appropriate HIV testing services, and the lack of information in general on youth experiences and views of HIV testing and counseling, the purpose of this study was to examine the experience of Aboriginal youth in the test encounter and ascertain their views on improving HIV testing and counseling.

\section{Method}

An exploratory mixed-method design was employed, including a cross-sectional survey and in-depth interviews (Mill et al., 2008). Here, we report on survey findings. Aboriginal health and friendship centers and
AIDS service organizations across Canada assisted with recruitment of participants. Aboriginal youth between 15 and 30 years of age, English or French speaking, were invited to participate. The term Aboriginal referred to youth who self-identified as First Nations (status or non-status), Métis, or Inuit.

A community-based research approach, incorporating the principles of community ownership, control, access and possession (OCAP) for research involving Aboriginal communities, which are consistent with Canadian Institutes of Health Research (CIHR) guidelines (2007), guided the study (Patterson, Jackson, \& Edwards, 2006). In order to honor OCAP principles, a community advisory committee (CAC; including Aboriginal youth and Elders) guided the study design, implementation and dissemination of the findings, and a participatory decision-making model was used. The participatory process allowed the research partners (including Aboriginal and nonAboriginal researchers) to jointly make research decisions and share results with community. While there is an emerging literature on the challenges of sharing results (e.g., Cooper, 2007, 2008), in this study we faced no difficulties in presenting results or other aspects of the research process. Ethics approval was obtained from all participating institutions.

\section{Survey instrument}

A self-administered survey was developed based on the published literature (Calzavara et al., 1998; Rotheram-Borus et al., 1997; Worthington \& Myers, 2002) in consultation with the CAC. The 49-question survey included items on the decision to test, the testing experience and, for youth living with HIV, experiences of HIV care. Questions related to the testing experience included a series of categorical response questions, three multiple response questions, three sets of Likert-scale questions, and two openended questions. The instrument was pre-tested with the $\mathrm{CAC}$ and recruiting organization members to enhance face and content validity; translated into French; and then pilot tested with two groups of Aboriginal youth, one English and one French speaking (total $n=19$ ).

\section{Data collection}

Convenience and network sampling (Wood \& RossKerr, 2006) were used to recruit youth to complete the surveys at 11 Aboriginal and Friendship Centers and AIDS Service Organizations in eight provinces/territories between January 2004 and February 2005. Participants were provided with a private space to complete the survey, and a research assistant was available to answer queries. The number of surveys 
collected at the 11 sites ranged from $14(3 \%)$ to 60 $(14 \%)$.

\section{Data analysis}

Bivariate analyses (Pearson's $\chi^{2}$ ) were used to compare selected test experiences by HIV test results. Open-ended survey item responses were listed verbatim, reviewed to establish categories, and then categorized according to the emergent categories. These categories were then tabulated, and representative quotations were selected for presentation.

\section{Results}

\section{Participants}

Four hundred and thirteen (413) Aboriginal youth completed the survey. Youth living in all 10 Canadian provinces and one territory participated in the study. Approximately half $(51 \%)$ of the survey respondents (210 of 413 Aboriginal youth) reported that they had ever been tested for HIV. Of the 210 youth who had tested for HIV, 26 youth $(12 \%)$ indicated they had tested HIV positive, and $21(10 \%)$ said their results were not clear or they had not received the result. See Table 1 for characteristics for the 210 youth who had tested for HIV.

The majority of youth $(61 \%)$ who had tested for HIV had their first HIV test in the five years prior to the survey (1999-2004), and only 13\% (28) of those who had ever tested for HIV reported that they had not tested within the last two years. The large majority $(81 \%)$ of youth had their most recent test in the community where they were currently living/had lived at the time of the test. The largest percentage (34\%) reported they had gone to a physician for their most recent HIV test, $17 \%$ reported testing at a hospital, $14 \%$ at a community/public health center and $14 \%$ at a walk-in clinic.

\section{The HIV test counseling experience}

\section{Information}

Survey participants were asked about types of information they received when they went for their most recent HIV test. Twenty-eight percent could not remember what information they were given, and almost one quarter $(23 \%)$ indicated they were not given any information (Table 2). Only one-fifth or less remembered being given information about specific issues such as protecting sexual partners from HIV $(20 \%)$. There were no significant differences in the types of information youth reported receiving by HIV test result (positive, negative or don't know/unclear).
Table 1. Characteristics of survey participants who had ever had an HIV test $(n=210)$.

\begin{tabular}{|c|c|c|}
\hline Variable $^{\mathrm{a}}$ & $N$ & Percent \\
\hline $\begin{array}{l}\text { Age ( Mean } \pm \text { SD years) range } \\
15-30 \text { years }\end{array}$ & \multicolumn{2}{|c|}{$23.4 \pm 4.2$} \\
\hline \multicolumn{3}{|l|}{ Gender } \\
\hline Male & 79 & 38 \\
\hline Female & 130 & 62 \\
\hline Transgender & 1 & 0.5 \\
\hline \multicolumn{3}{|l|}{ Aboriginal background } \\
\hline First Nations status & 132 & 65 \\
\hline First Nations non-status & 21 & 10 \\
\hline Métis & 29 & 14 \\
\hline Inuit & 15 & 7 \\
\hline Inuvaluit & 3 & 2 \\
\hline Other & 5 & 2 \\
\hline \multicolumn{3}{|c|}{ Languages spoken by youth (not mutually exclusive) } \\
\hline English & 205 & 98 \\
\hline Aboriginal language & 42 & 20 \\
\hline French & 32 & 15 \\
\hline \multicolumn{3}{|l|}{ Sexual identification } \\
\hline Heterosexual or straight & 162 & 77 \\
\hline Gay/lesbian/two-spirit/bisexual & 44 & 21 \\
\hline Other & 3 & 1 \\
\hline \multicolumn{3}{|l|}{ Marital status } \\
\hline Single & 126 & 61 \\
\hline Common-law relationship & 53 & 26 \\
\hline Married & 11 & 5 \\
\hline Separated/divorced/widowed & 13 & 6 \\
\hline \multicolumn{3}{|l|}{ Education } \\
\hline Grade eight or less & 27 & 13 \\
\hline Some high school & 100 & 48 \\
\hline Completed high school & 27 & 13 \\
\hline College/university & 2 & 11 \\
\hline Some post-secondary & 33 & 16 \\
\hline \multicolumn{3}{|l|}{ Religion and spirituality } \\
\hline Followed a religion & 80 & 38 \\
\hline $\begin{array}{l}\text { Followed traditional Aboriginal } \\
\text { practices }\end{array}$ & 74 & 35 \\
\hline \multicolumn{3}{|l|}{ Place of residence } \\
\hline $\begin{array}{l}\text { Living in urban centre, } \\
\text { population }>10,000\end{array}$ & 157 & 76 \\
\hline Own home/apartment & 94 & 36 \\
\hline Parents' home & 34 & 16 \\
\hline Friend's home & 24 & 12 \\
\hline Rooming house & 5 & 2 \\
\hline Shelter or safe house & 14 & 7 \\
\hline Hotel & 11 & 5 \\
\hline Homeless & 15 & 7 \\
\hline Other living arrangement & 11 & 5 \\
\hline \multicolumn{3}{|l|}{ Income sources } \\
\hline Had job & 65 & 31 \\
\hline Social support/welfare & 88 & 42 \\
\hline No income & 37 & 18 \\
\hline
\end{tabular}

${ }^{a}$ Certain variables do not add up to $100 \%$ as only some subvariables are shown. Many variables have missing data as participants could choose not to answer the survey questions or answer more than once per question. 
Table 2. Information provided at most recent HIV test $(n=210){ }^{\mathrm{a}}$

Frequency (percent)

\begin{tabular}{ll}
\hline I don't remember & $59(28)$ \\
Not given any information & $49(23)$ \\
Prevention for IDU & $46(22)$ \\
Protecting sexual partners & $42(20)$ \\
Effects of HIV disease & $42(20)$ \\
Support/counseling & $35(17)$ \\
Treatment for HIV infection & $29(14)$ \\
HIV reporting obligations & $22(10)$
\end{tabular}

${ }^{\mathrm{a} C}$ Column does not total due to multiple responses. Frequency and valid percent excludes missing cases.

Youth were also asked whether their questions were answered when they went for their most recent HIV test. Fifty percent indicated "yes, all of them," $26 \%$ indicated "yes, some of them," and $23.5 \%$ indicated "no." Youth who were HIV negative were more likely $\left(\chi^{2}(4, N=197)=14.7, p<0.01\right)$ to report they had their questions answered (56\%) than those who were HIV positive $(42 \%)$ or those who didn't know/results not clear $(25 \%)$.

\section{Perceptions of how treated}

Youth were also asked a series of questions about how they were treated during their most recent HIV test (Table 3). Over three quarters of participants felt they had been treated well, including $77 \%$ who said they were treated with respect. However, there was a significant minority who reported less positive perceptions, including being treated in a hostile $(19 \%)$ or bored (15\%) manner (Table 3 ).

Being asked about sexual behavior and alcohol and drug use

Seventy-two percent of youth who had been tested indicated that at their most recent HIV test they were asked about their past sexual behavior. The majority $(63 \%)$ of these indicated they felt comfortable when asked about sexual behaviors; however, a sizable minority reported less positive feelings, such as being scared $(39 \%)$ or embarrassed $(35 \%$; Table 4$)$. Similarly, the majority $(63 \%)$ of youth indicated they were comfortable when being asked questions about alcohol and drug use, but a significant minority reported more negative responses (see Table 5).

\section{Emotional reaction to HIV testing}

The survey included an open-ended question asking youth to describe their emotions when taking an HIV test. Seventy-nine percent of youth who had an HIV test responded. The majority of comments (106/166, or $64 \%$ ) summarized feelings of apprehension about the possibility of testing HIV positive, ranging from brief comments such as "holy shit scared" or "terrified" to more elaborate descriptions. One youth wrote, "I felt scared, blaming myself that my past caught up to me," and another wrote "I felt anxious even though I've been with the same partner for almost four years ... Maybe my partner has been unfaithful?" Another normalized the experience of anxiety: "I felt nervous because I had the actual HIV test done - feeling scared is a normal emotion." Beyond anxiety, six youth indicated that they felt "lost," "confused," or that they felt "negative about life."

Twelve (7\%) youth who responded to the survey question reported negative feelings about the HIV test experience itself. These youth indicated they were "embarrassed," "ashamed," or "uncomfortable," and one wrote "You wonder what the person who is testing you is thinking." One youth indicated, "I don't like being questioned by a white doctor." Two youth reported being upset because they had been tested without their knowledge.

Table 3. Perceptions of how youth were treated at their most recent test $(n=210){ }^{\mathrm{a}}$

\begin{tabular}{lccc}
\hline & Strongly agree/agree & Neutral & Strongly disagree/disagree \\
\cline { 2 - 4 } Characteristic: "I was treated [with]..." & \multicolumn{3}{c}{ Frequency (percent) } \\
\hline Care & $159(80)$ & $31(16)$ & $9(5)$ \\
Respect & $153(77)$ & $37(19)$ & $8(4)$ \\
Kindness & $151(76)$ & $40(20)$ & $8(4)$ \\
Hostility & $37(19)$ & $39(20)$ & $119(61)$ \\
In a bored, disinterested way & $29(15)$ & $47(24)$ & $120(61)$ \\
Fear & $24(12)$ & $27(14)$ & $144(74)$ \\
Discrimination & $22(11)$ & $32(16)$ & $141(72)$ \\
Avoidance & $19(10)$ & $32(16)$ & $145(74)$ \\
\hline
\end{tabular}

${ }^{a}$ Frequency and valid percent excludes missing cases (i.e., "No Response" and "Do Not Know," etc.). Percentages may not total $100 \%$ due to rounding. 
Table 4. Comfort with questions regarding sexual behavior $(n=199){ }^{\text {a }}$

\begin{tabular}{lccc}
\hline & Strongly agree/agree & Neutral & Strongly disagree/disagree \\
\cline { 2 - 4 } Characteristic: "I felt..." & Frequency (percent) \\
\hline Comfortable & $94(63)$ & $37(25)$ & $18(4)$ \\
Scared & $57(39)$ & $36(25)$ & $54(37)$ \\
Embarrassed & $52(35)$ & $42(28)$ & $55(37)$ \\
Ashamed & $35(24)$ & $31(21)$ & $83(56)$ \\
Upset & $29(20)$ & $32(22)$ & $87(59)$ \\
Angry & $20(14)$ & $32(22)$ & $96(65)$ \\
\hline
\end{tabular}

${ }^{a}$ Frequency and valid percent excludes missing cases (i.e., "No Response" and "Do Not Know," etc.). Percentages may not total $100 \%$ due to rounding.

A smaller percentage $(31 / 166,19 \%)$ reported little if any negative feelings about HIV testing. These youth reported feeling "normal" or "relaxed" when they had an HIV test. Three youth were more specific about why they felt this way; one wrote, "I felt comfortable because I was confident that I didn't have any HIV disease," and another wrote "I wanted to get tested for happiness." One youth reported feeling "brave."

\section{Advice from youth on improving the HIV testing experience}

Fifty-seven percent (121) of survey respondents who had experienced an HIV test provided comments in response to an open-ended question on how to improve the testing experience for others. The largest group of question respondents $(27 \%)$ used this space to encourage others to get tested for HIV despite the anxiety it may provoke, with comments like "Don't be scared, it's part of life and you'll feel ok after it's done with," or "Go for it, it might save your life and others' too." Five respondents suggested that youth should consult an elder or bring a relative or friend with them for support ("Bring a close friend to ensure you that everything will be okay").

Youth had a range of suggestions for the improvement of testing services, largely pertaining to the three professional relationship components: interpersonal style (respect); emotional support; and information (McQueen, 2000). Fifteen youth described "respectful" and "friendly" interpersonal styles, and other comments included in this category included, "Ask them in a way they don't feel ashamed," and "Have doctors that don't judge; it's not a bad thing to get tested." Comfort and emotional support were also commented on by six youth, for example, "Just to make the person feel at home - comfortable," and one youth advised test providers, "not to discriminate against them (i.e., youth) or treat them as if you are afraid of them." Six youth also indicated that "more information," or "more pre- and post-test counseling" would be helpful, and one commented on the information needs of health professionals (e.g., "Doctors and nurses strongly need to be aware of the disease").

In addition to the three major professional relationship components, four youth expressed concerns about confidentiality of the test results, informing individuals that they were being tested for HIV, and availability of HIV testing services. Three also suggested that HIV test results should be available more quickly. Finally, eight used the space to comment on their satisfaction with HIV testing experiences, with comments like "Nothing - maybe it's okay for me because I go to street nurses, and they are unjudgmental."

Table 5. Comfort with questions regarding alcohol and drug use at most recent HIV test $(n=195) .^{\text {a }}$

\begin{tabular}{lccc}
\hline & Strongly agree/agree & Neutral & Strongly disagree/disagree \\
\cline { 2 - 4 } Characteristic: "I felt..." & Frequency (percent) \\
\hline Comfortable & $78(63)$ & $36(29)$ & $10(8)$ \\
Scared & $29(24)$ & $30(24)$ & $64(52)$ \\
Embarrassed & $26(21)$ & $36(29)$ & $61(50)$ \\
Ashamed & $25(21)$ & $33(27)$ & $64(52)$ \\
Upset & $18(15)$ & $32(26)$ & $73(59)$ \\
Angry & $15(12)$ & $28(23)$ & $79(65)$ \\
\hline
\end{tabular}

${ }^{a}$ Frequency and valid percent excludes missing cases (i.e., "No Response" and "Do Not Know," etc.). Percentages may not total $100 \%$ due to rounding. 


\section{Discussion and conclusions}

Results from this study with Aboriginal youth are generally consistent with results from other studies in North America on test recipients' experiences with HIV testing. Aboriginal youth desire respectful, sensitive interactions in order to receive personalized information and allay anxiety over HIV and the social consequences of HIV; however, it appears that youth may not be receiving this information and support during HIV test counseling, or if they are, are not receiving it in a manner that helps them remember it (Obermeyer \& Osborn, 2007; Silvestre et al., 2000; Worthington \& Myers, 2002, 2003).

Other studies have found that test counseling can be a very useful tool for young clients to help ease their testing anxiety, especially if the counselor is reassuring (Michaels Opinion Research for the Kaiser Family Foundation, 1999). Unfortunately, some HIV test counselors are missing valuable opportunities to be emotionally supportive, and to provide useful information on HIV and how to reduce one's risk of becoming infected (Bucharski et al., 2006; Michaels Opinion Research for the Kaiser Family Foundation, 1999). Going for an HIV test may provoke anxiety, especially during the waiting period as clients worry whether their test will be HIV positive (Ransom, Siler, Peters, \& Maurer, 2005; Worthington \& Myers, 2003). At such an emotionally intense time, test providers need to be sensitive and ensure they are non-judgemntal and communicate a sense of understanding. Youth who sense judgment have been known to conceal the truth or simply walk out (Bucharski et al., 2006; Michaels Opinion Research for the Kaiser Family Foundation, 1999). The principle of respect is particularly important within Aboriginal cultures (Smylie et al., 2001).

There is reason to believe that strategies that make the testing experience easier for youth will increase their likelihood of voluntarily seeking an HIV test. This would include offering the test via saliva or urine rather than extracting blood (Michaels Opinion Research for the Kaiser Family Foundation, 1999; Peralta, Deeds, Hipszer, \& Ghalib, 2006), reducing wait times (Bucharski et al., 2006; Peralta et al., 2006), or providing more flexible hours. The move in many jurisdictions to rapid (point-of-care) testing may alleviate some of these concerns. Similarly, a study of high risk youth found that those who were given the option of telephone notification were more likely to receive their test results than those required to receive face-to-face notification (Tsu, Burm, Gilhooly, \& Sells, 2002).

Our results also suggest that cultural responsiveness within HIV testing services would create a more comfortable environment for Aboriginal youth. Comments from survey participants about needing to be treated with "respect," discomfort with "white doctors" and the desire to bring family or friends or consult an elder highlight important aspects of health care engagement for Aboriginal cultures (Smylie et al., 2001). Aboriginal people have suggested that incorporating more cultural (but not necessarily traditional) practices and spirituality would improve the testing process. Aboriginal women reported that they would find it helpful during the testing process to have the support of an Aboriginal elder, have native practices available (e.g., smudging), and be in a home-like environment (Bucharski et al., 2006). Cultural responsiveness to the many diverse Aboriginal cultures, and training in cultural competence for service providers are important components of HIV professional development and care (Barlow et al., 2008), as Aboriginal people in Canada may face significant stigma, discrimination, and misunderstanding from health care workers (Browne, 2007; Mill et al., 2009; Tang \& Browne, 2008).

This study was exploratory, and findings should be understood with several limitations in mind. The sampling methods used were not probability-based, but rather participants were recruited from convenience and network sampling to achieve diversity. Thus, while we recruited a relatively large sample (413 youth), the sample cannot be considered representative, and care should be exercised in applying results. For example, our sample was largely urban, and thus this survey does not capture perspectives of on-reserve or rural youth, where HIV services access may be more limited (Wordsman, Quantz, \& Clement, 2006). Nor was our sample size designed to allow for meaningful comparisons among First Nations, Métis, and Inuit youth. In addition, as this was a retrospective cross-sectional survey, participants reported on their perceptions of HIV testing experience a variable period after the test. Thus, recall effects and other factors will have influenced reported perceptions of the HIV test. Limitations aside, to the best of our knowledge, this is the first study to explore the HIV testing experience among Aboriginal youth in Canada.

\section{Acknowledgements}

The authors thank Chris Archibald and Tom Wong of the Public Health Agency of Canada (PHAC) for their contributions to the study as research team members. The authors thank the study participants for their willingness to share personal aspects of their lives. We also wish to acknowledge individual participants on the advisory committee, including Aboriginal elders, family members of persons diagnosed with HIV, and Aboriginal youth. We 
thank them for their guidance, perspectives, and wisdom. This project was supported by an operating grant provided by the Canadian Institutes of Health Research (CIHR). Dr. Worthington is a CIHR New Investigator.

\section{References}

Barlow, K., Loppie, C., Jackson, R., Akan, M., MacLean, L., \& Reimer, G. (2008). Culturally competent service provision issues experienced by aboriginal people living with HIV/AIDS. Pimatisiwin: A Journal of Aboriginal and Indigenous Community Health, 6(2), 155-180.

Branson, B.M., Handsfield, H.H., Lampe, M.A., Janssen, R.S., Taylor, A.W., Lyss, S.B., \& Clark, J.E. (2006). Revised recommendations for HIV testing of adults, adolescents, and pregnant women in health-care settings. MMWR Recommendations and Reports, 55(RR14), 1-17.

Browne, A.J. (2007). Clinical encounters between nurses and First Nations women in a Western Canadian hospital. Social Science \& Medicine, 64(10), 2165-2176.

Bucharski, D., Reutter, L.I., \& Ogilvie, L.D. (2006). You need to know where we're coming from": Canadian aboriginal women's perspectives on culturally appropriate HIV counseling and testing. Health Care for Women International, 27(8), 723-747.

Calzavara, L.M., Burchell, A.N., Myers, T., Bullock, S.L., Escobar, M., \& Cockerill, R. (1998). Condom use among aboriginal people in Ontario, Canada. International Journal of STD \& AIDS, 9(5), 272-279.

Canadian Institutes of Health Research (CIHR). (2007). Guidelines for health research involving aboriginal people. Ottawa, ON: Author.

Cooper, M. (2007). Sharing data and results in ethnographic research: Why this should not be an ethical imperative. Journal of Research on Human Research Ethics, 2(1), 3-19.

Cooper, M. (2008). Sharing data and results with study participants: Report on a survey of cultural anthropologists. Journal of Research on Human Research Ethics, 3(4), 19-34.

Grant, A.M., Jamieson, D.J., Elam-Evans, L.D., BeckSague, C., Duerr, A., \& Henderson, S.L. (2006). Reasons for testing and clinical and demographic profile of adolescents with non-perinatally acquired HIV infection. Pediatrics, 117(3), e468-e475.

Holtgrave, D., \& McGuire, J. (2007). Impact of counseling in voluntary counseling and testing programs for persons at risk for or living with HIV infection. Clinical Infectious Diseases, 45, S240-S243.

Hult, J.R., Maurer, S.A., \& Moskowitz, J.T. (2009). "I'm sorry, you're positive": A qualitative study of individual experiences of testing positive for HIV. AIDS Care, 21(2), 185-188.

Larkin, J., Flicker, S., Koleszar-Green, R., Mintz, S., Dagnin, M., \& Mitchell, C. (2007). HIV risk, systemic inequities, and aboriginal youth - widening the circle for HIV prevention programming. Canadian Journal of
Public Health-Revue Canadienne De Sante Publique, 98(3), 179-182.

Mackellar, D.A., Valleroy, L.A., Anderson, J.E., Behel, S., Secura, G.M., Bingham, T., ... Janssen, R.S. (2006). Recent HIV testing among young men who have sex with men: Correlates, contexts, and HIV seroconversion. Sexually Transmitted Diseases, 33(3), 183-192.

Marsiglia, F.F., Nieri, T., \& Stiffman, A.R. (2006). HIV/ AIDS protective factors among urban American Indian youths. Journal of Health Care for the Poor and Underserved, 17(4), 745-758.

McQueen, A. (2000). Nurse-patient relationships and partnership in hospital care. Journal of Clinical Nursing, 9(5), 723-731.

Mehrabadi, A., Craib, K.J.P., Patterson, K., Adam, W., Moniruzzaman, A., Ward-Burkitt, B., ... Spittal, P.M. (2008). The cedar project: A comparison of HIVrelated vulnerabilities amongst young aboriginal women surviving drug use and sex work in two Canadian cities. International Journal of Drug Policy, 19(2), 159168.

Michaels Opinion Research for the Kaiser Family Foundation. (1999). Hearing their voices: A qualitative research study on HIV testing and higher-risk teens. Menlo Park, CA: Kaiser Family Foundation.

Mill, J., Edwards, N., Jackson, R., Austin, W., MacLean, L., \& Reintjes, F. (2009). Accessing health services while living with HIV: Intersections of stigma. Canadian Journal of Nursing Research, 41(3), 168-185.

Mill, J.E., Jackson, R.C., Worthington, C.A., Archibald, C.P., Wong, T., Myers, T., ... Sommerfeldt, S. (2008). HIV testing and care in Canadian aboriginal youth: A community based mixed methods study. BMC Infectious Diseases, 8, 132. doi:10.1186/1471-2334-8-132

Monette, L., Albert, D., \& Waalen, J. (2001). Voices of twospirited men, a survey of aboriginal two-spirited men across Canada. Toronto, ON: 2-Spirited People of the 1st Nations.

Myers, T., Worthington, C., Haubrich, D.J., Ryder, K., \& Calzavara, L. (2003). HIV testing and counseling: Test providers' experiences of best practices. AIDS Education and Prevention, 15(4: Special issue), 309-319.

Norton, J., Miller, R., \& Johnson, M. (1997). Promoting HIV prevention: A problem identification approach to interventions in post-HIV test counselling. AIDS Care, 9(3), 345-353.

Obermeyer, C.M., \& Osborn, M. (2007). The utilization of testing and counseling for HIV: A review of the social and behavioral evidence. American Journal of Public Health, 97(10), 1762-1774.

Ontario Federation of Indian Friendship Centres. (2002). Tenuous connections: Urban aboriginal youth sexual health and pregnancy. Toronto, ON: Author.

Patterson, M., Jackson, R., \& Edwards, N. (2006). Ethics in aboriginal research: Comments on paradigms, process and two worlds. Canadian Journal of Aboriginal Community-Based HIV/AIDS Research, 1(Summer), 47-61. 
Peralta, L., Deeds, B.G., Hipszer, S., \& Ghalib, K. (2006). Barriers and facilitators to adolescent HIV testing. AIDS Patient Care STDS, 2007, 400-408.

Public Health Agency of Canada. (2006). HIV testing and counselling: Policies in transition? Research paper prepared for the international public health dialogue on HIV testing and counselling. Ottawa, ON: Author.

Public Health Agency of Canada. (2007a). HIV and AIDS in Canada. Surveillance report to December 21, 2006. Ottawa, ON: Surveillance and Risk Assessment Division, Centre for Infectious Disease Prevention and Control.

Public Health Agency of Canada. (2007b). HIV/AIDS epi updates: HIV/AIDS among aboriginal persons in Canada. Ottawa, ON: Surveillance and Risk Assessment Division, Centre for Infectious Disease Prevention and Control.

Public Health Agency of Canada. (2007c). HIV/AIDS epi updates: HIV/AIDS among youth in Canada. Ottawa, ON: Surveillance and Risk Assessment Division, Centre for Infectious Disease Prevention and Control.

Ransom, J.E., Siler, B., Peters, R.M., \& Maurer, M.J. (2005). Worry: Women's experience of HIV testing. Qualitative Health Research, 15(3), 382-393.

Rotheram-Borus, M.J., Gillis, J.R., Reid, H.M., Fernandez, M.I., \& Gwadz, M. (1997). HIV testing, behaviors, and knowledge among adolescents at high risk. The Journal of Adolescent Health, 20(3), 216-225.

Samet, J.H., \& Winter, M.R. (1997). Factors associated with HIV testing among sexually active adolescents: A Massachusetts survey. Pediatrics, 100(3), 371-377.

Schneir, A., Belzer, M.E., \& Adivi, C. (1998). Evaluation of youth HIV counseling and testing sites by undercover youth. The Journal of Adolescent Health, 22(2), 161161.

Shields, S.A., Wong, T., Mann, J., Jolly, A.M., Haase, D., Mahaffey, S., Moses, S., ... Sutherland, D. (2004). Prevalence and correlates of Chlamydia infection in Canadian street youth. Journal of Adolescent Health, 34(5), 384-390.

Silvestre, A.J., Gehl, M.B., Encandadela, J., \& Schelzel, G. (2000). A participant observation study using actors at 30 publicly funded HIV counselling and testing sites in
Pennsylvania. American Journal of Public Health, 90, 1096-1099.

Smylie, J., Lessard, P., Bailey, K., Couchie, C., Driedger, M., Eason, E.L., ... Yellowknife, N.T. (2001). A guide for health professionals working with aboriginal peoples: Cross cultural understanding. Journal Society of Obstetrics and Gynaecologists Canada, 23(2), 157-167.

Statistics Canada. (2008). Aboriginal peoples in Canada in 2006: Inuit, Métis and First Nations, 2006 census. Ottawa, ON. Retrieved from http://www12.statcan. ca/english/census06/data/highlights/Aboriginal/index. cfm?Lang=E.

Tang, S.Y., \& Browne, A.J. (2008). Race' matters: Racialization and egalitarian discourses involving aboriginal people in the Canadian health care context. Ethnicity \& Health, 13(2), 109-127.

Tsu, R.C., Burm, M.L., Gilhooly, J.A., \& Sells, C.W. (2002). Telephone vs. face-to-face notification of HIV results in high-risk youth. The Journal of Adolescent Health, 30(3), 154-160.

UNAIDS (Joint United Nations Programme on HIV/ AIDS). (2004). UNAIDS/WHO policy statement on HIV testing. Geneva: Author.

Weinhardt, L.S., Carey, M.P., Johnson, B., \& Bickham, N.L. (1999). Effects of HIV counselling and testing on sexual risk behavior: A meta-analytic review of published research, 1985-1997. American Journal of Public Health, 89, 1397-1405.

Wood, M., \& Ross-Kerr, J.C. (2006). Basic steps in planning nursing research: From question to proposal (6th ed). Sudbury, MA: Jones and Bartlett.

Wordsman, D., Quantz, D., \& Clement, K. (2006). HIV/ AIDS: Testing and risk behaviors among British Columbia's rural aboriginal population. International Journal of Circumpolar Health, 65(4), 313-321.

Worthington, C., \& Myers, T. (2002). Desired elements of HIV testing services: Test recipient perspectives. AIDS Patient Care and STDs, 16(11), 537-548.

Worthington, C., \& Myers, T. (2003). Factors underlying anxiety in HIV testing: Risk perceptions, stigma, and the patient-provider power dynamic. Qualitative Health Research, 13(5), 636-655. 